\title{
Possible dysmetabolic hyperferritinemia in hyperinsulinemic horses
}

\author{
Eleanor M. Kellon* and Kathleen M. Gustafson
}

\author{
Equine Cushing's and Insulin Resistance Group, Inc, 2307 Rural Road, Tempe, AZ 85282, USA
}

\begin{abstract}
Background: Hyperinsulinemia associated with equine metabolic syndrome and pituitary pars intermedia dysfunction is a risk factor for laminitis. Research in other species has shown elevated body iron levels as both a predictor and consequence of insulin resistance. In humans, this is known as dysmetabolic hyperferritinemia.

Aim: To explore the relationship between equine hyperinsulinemia and body iron levels.

Methods: We reviewed case histories and laboratory results from an open access database maintained by the Equine Cushing's and Insulin Resistance Group Inc. (ECIR). We identified 33 horses with confirmed hyperinsulinemia and laboratory results for serum iron, total iron binding capacity, and ferritin. Pearson correlation was used to test the relationship between insulin and iron indices. Additionally, we performed a secondary analysis of a previously reported controlled trial that was originally designed to test the correlation between iron status and the insulin response in horses. Here, we used a $t$-test to compare the mean values of insulin and ferritin between horses we categorized as normal or hyperinsulinemic based on their response to an oral challenge.

Results: Serum ferritin exceeded published reference range in 100\% of the horses identified from the ECIR database. There were no statistically significant associations between insulin indices (RISQI, log insulin) and iron indices (log serum iron, $\log$ TSI\%, log ferritin). There were trends for a negative association between RISQI and log iron $[r(31)=-0.33, p=0.058]$ and a positive association between age and ferritin $[r(30)=0.34, p=0.054]$. From the secondary data analysis of published data, we found significantly elevated ferritin $(p=0.05)$ in horses considered hyperinsulinemic by dynamic insulin testing compared to horses with a normal response.

Conclusion: These results suggest the potential for iron overload in hyperinsulinemic horses, a feature documented in other species and should stimulate further study into the relationship between insulin and iron dysregulation in the horse.
\end{abstract}

Keywords: Equine, Ferritin, Hyperinsulinemia, Iron overload.

\section{Introduction}

The relationship between iron regulation, glucose homeostasis, insulin action, and secretion is complex. High body burdens of iron have been associated with decreased insulin sensitivity in humans (Huang et al., 2015; Ryan et al., 2018; Zafar et al., 2015) and increased risk of developing insulin resistance/hyperinsulinemia and type 2 diabetes mellitus (Simcox and McClain, 2013) while reduction of iron levels via phlebotomy may improve metabolic parameters (Fargion et al., 2005; Houschyar et al., 2012). Similarly, several species of captive birds and mammals are known to develop dietary iron overload and subsequent insulin resistance on zoo diets, including the close equine relatives; the tapir and black rhinoceros (Clauss and Paglia, 2012). Hyperinsulinemia is a component of equine metabolic syndrome (EMS) and may be a feature of pituitary pars intermedia dysfunction (PPID) (Frank and Tadros, 2014). Iatrogenic hyperinsulinemia while maintaining euglycemia induces laminitis in both ponies (Asplin et al., 2007) and horses (de Laat et al., 2010). Hyperinsulinemia is now believed to be by far the most common cause of naturally occurring laminitis
(Morgan et al., 2015) and is a significant welfare issue with population studies showing $18 \%$ to $27 \%$ of horses/ ponies being hyperinsulinemic (Durham et al., 2019). Smith et al. (1984) published a ferritin normal range which was correlated to the iron levels in the liver and spleen. That work, including the development of species-specific assays, remains the gold standard today. Smith established that, as in other species, ferritin is the best index of the liver and spleen nonheme iron stores in horses, with a high correlation between serum ferritin and hepatic and splenic tissue levels.

Recognition of the link between iron and insulin resistance dates back to the early 1900s (Root, 1929). Since then, there has been considerable investigation of the role of iron in adipose tissue, effects of iron on glucose homeostasis, and the interplay between insulin and iron trafficking (Fernandez-Real et al., 2002) Suggested roles for insulin include stimulating enhanced uptake of extracellular iron and inducing relocation of transferrin receptors (Fernandez-Real et al., 2015). A genetic component is likely, suggested by significantly higher insulin and iron indices and a significant positive correlation between insulin and 
serum iron in the non-diabetic offspring of type 2 diabetics (Zafar et al., 2015).

While the relationship between iron and insulin resistance has been the topic of intense research investigation in humans and other species, it has been largely unrecognized by equine medicine. There are more reports describing the relationship between iron, inflammation, and insulin sensitivity in rhinos than in horses because investigators recognized the relationship between metabolic disease and iron overload in black rhinos (Schook et al., 2015). To the authors' knowledge, there is only a single controlled pilot study describing the relationship between iron status and the insulin response in horses (Nielsen et al., 2012). Nielsen et al. measured the insulin response to a glycemic challenge (dextrose or corn added to feed) and found a positive correlation between serum ferritin and insulin. There was also a conference presentation showing significantly elevated iron indices in hyperinsulinemic horses compared to herd mates but the herd mate controls, while phenotypically normal, were not formally tested for hyperinsulinemia (Kellon, 2006). Our goal in this short communication is to report ferritin levels in hyperinsulinemic horses in order to generate further investigation into equine insulin and iron dysregulation.

\section{Materials and Methods}

We performed a retrospective review of case histories and laboratory results; specifically, insulin and iron indices, obtained from a database maintained by the Equine Cushing's and Insulin Resistance Group Inc. (ECIR) https://ecir.groups.io. As members of the ECIR Group, horse owners provided detailed case histories and laboratory reports to the database. Blood samples were authorized by owners and collected by their attending veterinarian as part of the routine care and treatment of their animals.

We also performed a secondary analysis of previously reported ferritin levels in horses that had normal versus hyperinsulinemic responses to an oral challenge (Nielsen et al., 2012). Because Nielsen's dextrose challenge used a lower $(0.25 \mathrm{~g} / \mathrm{kg} \mathrm{BW})$ dose than recommended for the in-feed dextrose challenge (Durham et al., 2019), we used the results of the peak insulin response to pelletedcorn feeding (fed at $1.5 \mathrm{~g} / \mathrm{kg} \mathrm{BW}=1.05 \mathrm{~g} / \mathrm{kg} \mathrm{BW}$ starch). This approach is justified by de Laat and Sillence (2017) who established equivalence between an oral dextrose load in a high fiber carrier and an equivalent amount of carbohydrate as grain.

\section{Animals}

\section{ECIR database}

We reviewed the case histories of privately owned horses of various breeds (20 geldings, 13 mares) ranging in age from 8 to 29 years (mean age $17.9 \pm 5.8$ ). Breed, age, sex, iron, and insulin indices for individual animals are listed in Table 1. None of the horses were reported to have factors which could influence ferritin levels (McLean et al., 1987; Smith et al., 1984), including active laminitis, injuries, evidence of other disease, pregnancy, or formal exercise within 48 hours prior to sampling (Hyyppä et al., 2002) and were not in regular work. Horses were on forage only or forage predominant diets and had no current supplemental iron intake or past history of supplemental iron other than what may have been present in commercial concentrates.

\section{Nielsen study}

Sixteen Arabian horses were included (eight geldings, eight mares) classified as young (age 3 years, $n=9$ ) or older $(>10$ years, $n=7)$. Details of the feeding protocol, sample collection, and testing from Nielsen et al. (2012) are found in the original publication.

\section{Insulin and iron indices}

All samples were drawn and processed by owners' private attending veterinarians. Blood for serum iron, total iron binding capacity (TIBC), and ferritin was processed according to instructions from the Comparative Hematology Laboratory, Kansas State University (KSU) including avoiding hemolysis while collecting serum samples, removing serum from clot into a capped plastic tube, and freezing at $-20^{\circ} \mathrm{C}$. Samples were shipped to KSU overnight with ice gel packs or dry ice. Testing for ferritin was performed as detailed by the laboratory founder (Smith et al., 1984). Blood for insulin determination was drawn in the nonfasted state with horses having access only to soaked hay or hay with combined ethanol soluble carbohydrate and starch of $\leq 10 \%$ for 12 or more hours prior to sampling. Venous samples were collected into EDTA or serum tubes, processed, and shipped according to sample handling instructions from the Animal Health Diagnostic Laboratory at Cornell University School of Veterinary Medicine and analyzed via validated radioimmunoassay.

The proxy for insulin sensitivity [reciprocal of the square root of insulin: (RISQI)] was calculated from basal plasma insulin as follows: RISQI $=$ Insulin $^{-0.5}(=1 / \sqrt{ }$ insulin $)$. Transferrin saturation index (TSI) as a marker of possible disease/inflammatory effects on iron homeostasis and ferritin was calculated from serum iron and TIBC by the equation Iron/TIBC $\times 100$.

For the retrospective analysis of Nielsen et al. (2012), we used current guidelines to define hyperinsulinemia (Durham et al., 2019). We grouped animals based on the published report of their response to the pelleted corn feeding challenge; HYP (hyperinsulinemia) and NORM (normoinsulinemia).

\section{Statistical analysis}

\section{ECIR sample}

Insulin and iron indices obtained from the ECIR database were tested for normality using the ShapiroWilk test. Data with abnormal distributions (serum iron, TSI\%, ferritin, and insulin) were log-transformed to achieve a normal distribution; RISQI was normally 
Table 1. Insulin and iron data of horses from the ECIR database.

\begin{tabular}{|c|c|c|c|c|c|c|c|}
\hline Breed & $\begin{array}{c}\text { Age } \\
\text { (years) }\end{array}$ & Sex & $\begin{array}{c}\text { Iron } \\
(\mu \mathrm{g} / \mathrm{dl})\end{array}$ & TSI\% & $\begin{array}{c}\text { Ferritin } \\
(\mathrm{ng} / \mathrm{ml})\end{array}$ & $\begin{array}{l}\text { Insulin } \\
(\mu \mathrm{I} U / \mathrm{ml})\end{array}$ & $\begin{array}{c}\text { RISQI } \\
(\mathrm{uIU} / \mathrm{l})^{-0.5}\end{array}$ \\
\hline Friesian & 9 & Mare & 176 & 50.4 & 620 & 259.0 & 0.06 \\
\hline Arabian & 15 & Gelded & 277 & 49.1 & - & 168.5 & 0.08 \\
\hline Arabian & 19 & Gelded & 220 & 47.1 & 430 & 55.8 & 0.13 \\
\hline Quarterhorse & 17 & Gelded & 214 & 38.4 & 855 & 38.7 & 0.16 \\
\hline Warmblood/Arabian & 16 & Gelded & 158 & 40.4 & 694 & 26.7 & 0.19 \\
\hline Arabian & 19 & Gelded & 213 & 43.3 & 449 & 47.5 & 0.15 \\
\hline Morgan & 13 & Mare & 231 & 50.9 & 373 & 101.0 & 0.10 \\
\hline Tennessee Walker & 14 & Gelded & 224 & 44.3 & 308 & 107.5 & 0.09 \\
\hline Appaloosa & 15 & Gelded & 194 & 48.7 & 980 & 104.0 & 0.09 \\
\hline Saddlebred & 8 & Gelded & 170 & 41.4 & 340 & 51.7 & 0.14 \\
\hline Kentucky Mountain & 13 & Gelded & 190 & 47.9 & 268 & 125.0 & 0.09 \\
\hline Warmblood & 16 & Gelded & 201 & 57.8 & 479 & 47.7 & 0.14 \\
\hline Arabian & 18 & Gelded & 154 & 57.5 & 430 & 55.9 & 0.13 \\
\hline Miniature & 24 & Mare & 345 & 61.7 & 458 & 121.7 & 0.09 \\
\hline Morgan & 20 & Gelded & 352 & 69.4 & 261 & 22.0 & 0.21 \\
\hline Gypsy Vanner & 11 & Gelded & 157 & 39.6 & 381 & 31.2 & 0.18 \\
\hline DraftXTb & 21 & Gelded & 141 & 44.9 & 656 & 27.9 & 0.19 \\
\hline ShireXPinto & 21 & Mare & 125 & 44.2 & 490 & 41.8 & 0.14 \\
\hline Morgan & 22 & Gelded & 308 & 58.1 & 308 & 98.6 & 0.10 \\
\hline Rocky Mountain & 18 & Gelded & 312 & 70.4 & 370 & 24.0 & 0.20 \\
\hline Thoroughbred & 27 & Mare & 137 & 37.4 & 758 & 23.0 & 0.21 \\
\hline Haflinger & 9 & Mare & 318 & 92.4 & 266 & 45.8 & 0.15 \\
\hline Rocky Mountain & 15 & Mare & 152 & 44.9 & 356 & 52.0 & 0.14 \\
\hline Arabian & 12 & Mare & 140 & 41.2 & 317 & 47.0 & 0.15 \\
\hline Arabian & 25 & Gelded & 157 & 73.3 & 435 & 79.0 & 0.11 \\
\hline Warmblood & 17 & Mare & 160 & 45.3 & 324 & 36.5 & 0.17 \\
\hline Warmblood & 18 & Mare & 121 & 33.4 & 542 & 27.0 & 0.19 \\
\hline Warmblood & 10 & Mare & 269 & 65.1 & 479 & 42.4 & 0.15 \\
\hline Spotted Saddle & 29 & Gelded & 289 & 74.1 & 722 & 109.2 & 0.09 \\
\hline Quarterhorse & 18 & Gelded & 214 & 38.5 & 844 & 38.7 & 0.16 \\
\hline Thoroughbred & 27 & Mare & 137 & 34 & 758 & 21.0 & 0.22 \\
\hline Morgan & 27 & Mare & 168 & 34 & 271 & 78.7 & 0.11 \\
\hline Warmblood & 27 & Gelded & 307 & 54.9 & 982 & 208.0 & 0.07 \\
\hline
\end{tabular}

distributed. We used Pearson correlation to test the relationship between iron and insulin indices and age.

\section{Nielsen sample}

Data from Nielsen et al. (2012) were similarly tested for normality. Ferritin was normally distributed, and peak insulin to pelleted-corn was log-transformed to a normal distribution. For these data, we compared independent means of log peak insulin and ferritin between groups NORM and HYP using an unpaired $t$-test. Results were considered significant at $p \leq 0.05$, and trends reported at $p \leq 0.1$.

\section{Results and Discussion}

ECIR sample

Mean \pm SD for normally distributed data (age, RISQI) and median (IQR) for log-transformed data (serum iron, TIBC, and ferritin), as well as reference values, are listed in Table 2. All animals were confirmed hyperinsulinemic by basal insulin $(>20 \mathrm{uIU} / \mathrm{ml})$ (Durham et al., 2019) and screened within or below the lowest quintile of insulin sensitivity by RISQI (0.159 uIU/1 $\left.{ }^{-0.5}\right)$ (Treiber et al., 2005). One horse was 
Table 2. Mean insulin level and iron indices in ECIR horses with reference ranges.

\begin{tabular}{lcc}
\hline Parameters & $\begin{array}{c}\text { Mean } \pm \text { SD; } \\
\text { Median } \\
\text { (IQR) }\end{array}$ & $\begin{array}{c}\text { Laboratory or } \\
\text { published reference } \\
\text { range }\end{array}$ \\
\hline Age (years) & $17.9 \pm 5.8$ & \\
\hline $\begin{array}{l}\text { Insulin } \\
(\mathrm{uIU} / \mathrm{ml})\end{array}$ & $47.7(66.6)$ & $\begin{array}{c}<0 \mathrm{uIU} / \mathrm{ml} ; \\
\text { (Frank and Tadros, 2014) }\end{array}$ \\
\hline RISQI & $0.14 \pm 0.05$ & $\begin{array}{c}>0.32 ; \\
\text { (Treiber } \text { et al., 2005) }\end{array}$ \\
\hline Iron (ug/dl) & $194(115)$ & $\begin{array}{c}50-198 \mathrm{ug} / \mathrm{dl} \\
\text { (Smith } \text { et al., 1984) }\end{array}$ \\
\hline TSI\% & $47.1(16.9)$ & $\begin{array}{c}30 \%-40 \% \\
\text { (McLean } \text { et al., 1987) } \\
\text { 43-261 ug/dl }\end{array}$ \\
\hline Ferritin (ng/ml) & $442(343)$ & (Smith et al., 1984) \\
\hline
\end{tabular}

missing results for ferritin. In the 32 animals with results for ferritin, $100 \%$ exceeded the published normal range. Results of the Pearson correlation indicated no statistically significant associations between insulin indices (RISQI, log insulin) and iron indices (log serum iron, $\log \mathrm{TSI} \%$, and $\log$ ferritin). We found trends for a negative association between RISQI and log iron $[r(31)=-0.33, p=0.058]$ and a positive association between age and ferritin $[r(30)=0.34, p=0.054]$.

\section{Nielsen sample}

The peak insulin response to pelleted corn in 6 of the 16 horses was abnormally high and a 7th horse was only $1 \mathrm{uIU} / \mathrm{ml}$ below the $>85 \mathrm{uIU} / \mathrm{ml}$ threshold. These seven animals made up the HYP group. The remaining nine animals with typical responses to the corn feeding challenge made up the NORM group. Log transformed peak insulin to corn feeding was significantly higher in HYP horses $(t=5.40, p=<0.0001)$; raw data; $247 \mathrm{uIU} /$ $\mathrm{ml} \pm 207$ compared to $40.9 \mathrm{uIU} / \mathrm{ml} \pm 13.7$ for NORM horses (Fig. 1). Similarly, ferritin was significantly higher in the HYP horses $556.3 \pm 178.3$ compared to $374.6 \pm 165.0$ in NORM horses; $(t=-2.11, p=0.05)$ (Fig. 1). We should point out that Nielsen et al. (2012) found a significant correlation between serum ferritin and insulin response to dextrose or pelleted corn feeding; however, the significance of the correlation was largely driven by one highly hyperinsulinemic horse. We approached the data differently by grouping the horses into hyperinsulinemic vs. normal in response to corn feeding, correcting the skewed insulin data distribution by log-transformation, and testing the difference in group means.

All horses from the ECIR database fulfilled the definition of EMS by being hyperinsulinemic at baseline plus one or more of the characteristics of generalized or regional adiposity, weight loss resistance, hyperlipidemia,

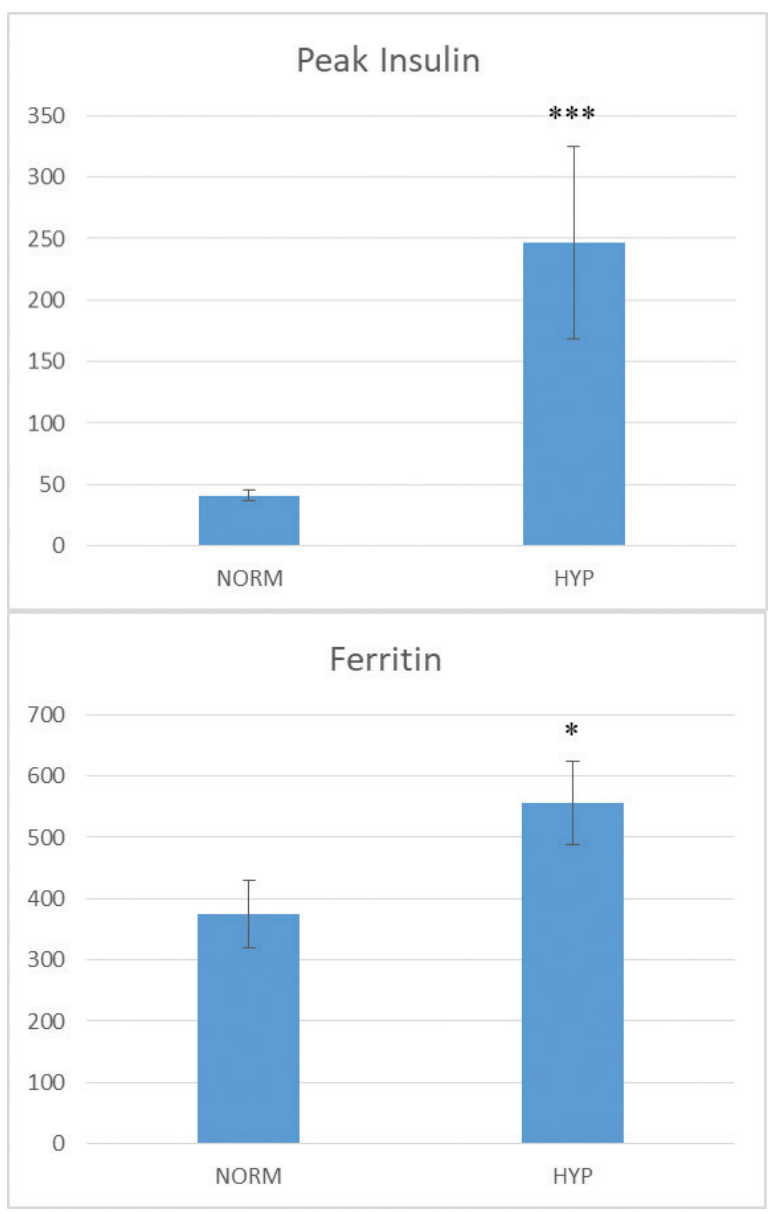

Fig. 1. Raw (non-transformed) data from Nielsen et al. (2012). Mean (+/-) SE for peak insulin to pelleted corn feeding (top) and ferritin (bottom) after grouping animals as normoinsulinemic (NORM) versus hyperinsulinemic (HYP) $(* * * p=<0.0001, * p=0.05)$.

and laminitis history. Tissue insulin resistance per se was not confirmed by intravenous testing. However, RISQI values fell within or below the lowest quintile of insulin sensitivity as determined by Treiber et al. (2005) using FSIGT to validate the proxies. RISQI has been used as a surrogate for intravenous testing in other published studies (Turner et al., 2011). Sensitivity of the insulin resistance proxies is known to be poor but the specificity of RISQI is $85 \%$. Decreased hepatic/ tissue insulin clearance has been established as a factor in hyperinsulinemia but it has not been shown that hyperinsulinemia caused by reduced hepatic/tissue metabolism of insulin can occur outside of the insulinresistant state or as a prodrome. Therefore, while it may be a factor in addition to tissue insulin resistance which contributes to the hyperinsulinemia, it does not necessarily occur independently of it.

All horses in our ECIR retrospective analysis had hyperinsulinemia and elevated ferritin. We also 
found a trend for lower RISQI (higher insulin) with higher serum iron, which may reflect increased iron absorption. Mice placed on a diet designed to induce insulin resistance were found to show increased hepatic iron and decreased hepcidin expression prior to the development of insulin resistance, suggesting increased iron absorption is an integral and early event (Tsuchiya et al., 2013).

The lack of a significant linear relationship between insulin and ferritin was not unexpected given that both iron overload and hyperinsulinemia are multifactorial states. The degree of hyperinsulinemia may be influenced by such factors as genetics, diet, exercise, and PPID. Although care was taken to exclude animals with current factors known to influence ferritin, age, and varying iron levels in forage and water over the life of the animal could contribute to the degree of iron overload, as would the existence of dietary factors interfering with iron absorption.

We found a trend for higher ferritin with advancing age in this small sample, a possibility suggested by others (Smith et al., 1984). Since there is no avenue of excretion for excess iron, the degree of iron overload will represent iron accumulation over time and also may be more representative of the duration of hyperinsulinemia rather than hyperinsulinemia per se or degree of hyperinsulinemia.

Considerable interplay has been described between iron metabolism and metabolic syndrome and type 2 diabetes in humans (Kunutsor et al., 2013), laboratory animals (Wang et al., 2015), and zoo animals (Clauss and Paglia, 2012). Increased body iron stores are a risk factor for insulin resistance and the development of type 2 diabetes (Kunutsor et al., 2013). Reduction of iron via phlebotomy may improve insulin sensitivity in humans (Fernandez-Real et al., 2002) while a low heme iron diet reduces the iron status and risk (Hua et al., 2001). Research in insulin-resistant, type 2 diabetic rats have demonstrated increased intestinal absorption of iron (Weeks et al., 1989), making the iron-insulin link a self-perpetuating situation. Our data suggest similar interactions between hyperinsulinemia and body iron burden that could exist in the horse and are directions for future study.

Many factors other than hyperinsulinemia may be associated with altered iron status. Serum ferritin is also an acute phase reactant. Therefore, exercise, illness, and injury are known to increase serum ferritin levels. Pregnancy reduces ferritin levels to guarantee adequate iron availability for the fetus. Care was taken to exclude horses with a history of these possible confounders. The majority (79\%) of horses in our sample had high TSI while none were low. Low TSI is associated with inflammation (McLean et al., 1987; Rambod et al., 2008). The observation of normal to elevated TSI in the sample where all horses had elevated ferritin is further evidence of no significant inflammatory component in this cohort, compatible with the elevated ferritins indicating iron overload.

We recognize limitations to this retrospective analysis. This was not a prospective, controlled study comparing age-matched groups with and without hyperinsulinemia. The existing evidence investigating the bidirectional relationship between iron and hyperinsulinemia in horses is extraordinarily limited despite considerable scientific inquiry in other species. To the authors' knowledge, Nielsen et al. (2012) is the only controlled study that used an equine model, but as a proxy for captive rhinos. A controlled, prospective study of sufficient power using dynamic tests of insulin sensitivity, diet control and analysis, iron indices, and inflammatory markers or other factors influencing ferritin is needed to disentangle the complex relationship between insulin and iron in the horse.

The term for the relationship between body iron stores and insulin in humans is dysmetabolic hyperferritinemia (Stechemesser et al., 2017). The influence is bidirectional, with iron burden influencing insulin levels and vice versa. Iron has been suggested as a therapeutic target for people with, or at risk of, hyperinsulinemia and type 2 diabetes (Fernandez-Real et al., 2015) as well as laboratory animal models (Minamiyama et al., 2010), Macaws (Gancz et al., 2007), dolphins (Venn-Watson et al., 2013), and other zoo species. If the situation is confirmed to be similar in horses, iron may be a modifiable risk factor for hyperinsulinemia.

While even severe iron overload can occur in horses without evidence of metabolic syndrome (Theelen et al., 2019), and iron is unlikely to be an independent causal factor, the interplay uncovered in other species shows this is a factor worthy of further investigation. This preliminary retrospective investigation should increase awareness of the potential for iron overload in hyperinsulinemic horses and stimulate further study into the relationship between insulin and iron dysregulation.

\section{Acknowledgments}

The authors extend their gratitude to the horse owners and veterinarians who provided the case histories and laboratory reports needed for this communication and to the volunteers of the Equine Cushing's and Insulin Resistance Group Inc. who organize and maintain the database.

\section{Conflicts of interest}

The authors declare that there are no conflicts of interest.

\section{Author contributions}

E.K.: concept/design, acquisition of data, drafting of the manuscript, critical revision of the manuscript, and approval of the manuscript. K.G: preparation of figures, statistical analysis, drafting of the manuscript, critical revision of the manuscript, and approval of the manuscript. 


\section{Ethical approval}

Not necessary - a retrospective review of case histories and published data.

\section{References}

Asplin, K.E., Sillence, M.N., Pollitt, C.C. and McGowan, C.M. 2007. Induction of laminitis by prolonged hyperinsulinaemia in clinically normal ponies. Vet. J. 174, 530-535.

Clauss, M. and Paglia, D.E. 2012. Iron storage disorders in captive wild mammals: the comparative evidence. J. Zoo Wildl. Med. 43, S6-18.

de Laat, M. Frank, N., McGowan, C.M., MenziesGow, N.J., Roelfsema, E., Vervuert, I., Feige, K. and Fey, K. 2019. ECEIM consensus statement on equine metabolic syndrome. J. Vet. Intern. Med. 33, 335-349.

Fargion, S., Dongiovanni, P., Guzzo, A., Colombo, S., Valenti, L. and Fracanzani, A.L. 2005. Iron and insulinA., McGowan, C.M., Sillence, M.N. and Pollitt, C.C. 2010. Equine laminitis: Induced by $48 \mathrm{~h}$ hyperinsulinaemia in Standardbred horses. EVJ Equine Vet. J. 42, 129-135.

de Laat, M.A. and Sillence, M.N. 2017. The repeatability of an oral glucose test in ponies. Equine Vet. J. 49, 238-243.

Durham, A.E., resistance. Aliment. Pharmacol. Ther. 22(Suppl 2), 61-63.

Fernandez-Real, J.M., McClain, D. and Manco, M. 2015. Mechanisms linking glucose homeostasis and iron metabolism toward the onset and progression of type 2 diabetes. Diabetes Care 38, 2169-2176.

Fernandez-Real, J.M., Penarroja, G., Castro, A., LopezBermejo, A., Garcia-Bragado, F. and Ricart, W. 2002. Blood letting in high-ferritin type 2 diabetes mellitus. Effects on insulin sensitivity and beta-cell function. Diabetes 51, A137.

Frank, N. and Tadros, E.M. 2014. Insulin dysregulation. Equine Vet. J. 46, 103-112.

Gancz, A.Y., Wellehan, J.F., Boutette, J., Malka, S., Lee, S.E., Smith, D.A. and Taylor, M. 2007. Diabetes mellitus concurrent with hepatic haemosiderosis in two macaws (Ara severa, Ara militaris). Avian Pathol. 36, 331-336.

Houschyar, K.S., Ludtke, R., Dobos,G.J., Kalus, U., Broecker-Preuss, M., Rampp, T., Brinkhaus, B. and Michalsen, A. 2012. Effects of phlebotomyinduced reduction of body iron stores on metabolic syndrome: results from a randomized clinical trial. BMC Med. 10, 54.

Hua, N.W., Stoohs, R.A. and Facchini, F.S. 2001. Low iron status and enhanced insulin sensitivity in lactoovo vegetarians. Br. J. Nutr. 86, 515-519.

Huang, J., Karnchanasorn, R., Ou, H.Y., Feng, W., Chuang, L.M., Chiu, K.C. and Samoa, R. 2015. Association of insulin resistance with serum ferritin and aminotransferases-iron hypothesis. World J. Exp. Med. 5, 232-243.
Hyyppä, S., Höyhtyä, M., Nevalainen, M. and Pösö, A.R. 2002. Effect of exercise on plasma ferritin concentrations: implications for the measurement of iron status. EVJ Equine Vet. J. 34, 186-190.

Kellon, E.M. 2006. Iron status of hyperinsulimemic/ insulin resistant horses. In 3rd Annual European Equine Health and Nutrition Congress, 1-2. Ghent University, Belgium.

Kunutsor, S.K., Apekey, T.A., Walley, J. and Kain, K. 2013. Ferritin levels and risk of type 2 diabetes mellitus: an updated systematic review and metaanalysis of prospective evidence. Diabetes-Metab. Res. 29, 308-318.

McLean, L.M., Hall, M.E. and Bell, J.E. 1987. Evaluation of serum iron, total iron binding capacity, unbound iron binding capacity, percent saturation and serum ferritin in the equine. In Proceedings of the $10^{\text {th }}$ Equine Nutrition and Physiology Society Symposium, Ft. Collins, Colorado, pp: 443-446.

Minamiyama, Y., Takemura, S., Kodai, S., Shinkawa, H., Tsukioka, T., Ichikawa, H., Naito, Y., Yoshikawa, T. and Okada, S. 2010. Iron restriction improves type 2 diabetes mellitus in Otsuka Long-Evans Tokushima fatty rats. Am. J. Physiol. Endocrinol. Metab. 298, E1140-1149.

Morgan, R., Keen, J. and McGowan, C. 2015. Equine metabolic syndrome. Vet. Rec. 177, 173-179.

Nielsen, B.D., Vick, M.M. and Dennis, P.M. 2012. A Potential Link between Insulin Resistance and Iron Overload Disorder in Browsing Rhinoceroses Investigated through the Use of an Equine Model. J. Zoo Wildl. Med. 43, S61-S65.

Rambod, M., Kovesdy, C.P. and Kalantar-Zadeh, K. 2008. Combined high serum ferritin and low iron saturation in hemodialysis patients: the role of inflammation. Clin. J. Am. Soc. Nephrol. 3, 16911701 .

Root, H.F. 1929. Insulin resistance and bronze diabetes. New Engl. J. Med. 201, 201-206.

Ryan, B.J., Van Pelt, D.W., Guth, L.M., Ludzki, A.C., Gioscia-Ryan, R.A., Ahn, C., Foug, K.L. and Horowitz, J.F. 2018. Plasma ferritin concentration is positively associated with in vivo fatty acid mobilization and insulin resistance in obese women. Exp. Physiol. 103, 1443-1447.

Schook, M.W., Wildt, D.E., Raghanti, M.A., Wolfe, B.A. and Dennis, P.M. 2015. Increased inflammation and decreased insulin sensitivity indicate metabolic disturbances in zoo-managed compared to freeranging black rhinoceros (Diceros bicornis). Gen. Comp. Endocrinol. 217-218, 10-19.

Simcox, J. A. and McClain, D.A. 2013. Iron and diabetes risk. Cell Metab. 17, 329-341.

Smith, J.E., Moore, K., Cipriano, J.E. and Morris, P.G. 1984. Serum ferritin as a measure of stored iron in horses. J. Nutr. 114, 677-681.

Stechemesser, L., Eder, S.K., Wagner, A., Patsch, W., Feldman, A., Strasser, M., Auer, S., Niederseer, D., 
Huber-Schonauer, U., Paulweber, B., Zandanell, S., Ruhaltinger, S., Weghuber, D., Haschke-Becher, E., Grabmer, C., Rohde, E., Datz, C., Felder, T.K. and Aigner, E. 2017. Metabolomic profiling identifies potential pathways involved in the interaction of iron homeostasis with glucose metabolism. Mol. Metab. 6, 38-47.

Theelen, M.J.P., Beukers, M., Grinwis, G.C.M. and Sloet van Oldruitenborgh-Oosterbaan, M.M. 2019. Chronic iron overload causing haemochromatosis and hepatopathy in 21 horses and one donkey. Equine Vet. J. 51, 304-309.

Treiber, K.H., Kronfeld, D.S., Hess, T.M., Boston, R.C. and Harris, P.A. 2005. Use of proxies and reference quintiles obtained from minimal model analysis for determination of insulin sensitivity and pancreatic beta-cell responsiveness in horses. Am. J. Vet. Res. 66, 2114-2121.

Tsuchiya, H., Ebata, Y., Sakabe, T., Hama, S., Kogure, K. and Shiota, G. 2013. High-fat, high-fructose diet induces hepatic iron overload via a hepcidinindependent mechanism prior to the onset of liver steatosis and insulin resistance in mice. Metabolism $62,62-69$.
Turner, S.P., Hess, T.M., Treiber, K., Mello, E.B., Souza, B.G. and Almeida, F.Q. 2011. Comparison of Insulin Sensitivity of Horses Adapted to Different Exercise Intensities. J. Equine Vet. Sci. 31, 645-649.

Venn-Watson, S., Smith, C.R., Stevenson, S., Parry, C., Daniels, R., Jensen, E., Cendejas, V., Balmer, B., Janech, M., Neely, B.A. and Wells, R. 2013. Bloodbased indicators of insulin resistance and metabolic syndrome in bottlenose dolphins (Tursiops truncatus). Front Endocrinol. (Lausanne) 4, 136.

Wang, X., Fang, X. and Wang, F. 2015. Pleiotropic actions of iron balance in diabetes mellitus. Rev. Endocr. Metab. Disord. 16, 15-23.

Weeks, B.R., Smith, J.E., DeBowes, R.M. and Smith, J.M. 1989. Decreased serum iron and zinc concentrations in cattle receiving intravenous dexamethasone. Vet. Pathol. 26, 345-346.

Zafar, U., Qureshi, H.J. and Imran, M. 2015. Comparison of Iron Status and Insulin Resistance between Non-Diabetic Offsprings of Type 2 Diabetics and Non-Diabetics. J. Ayub. Med. Coll. Abbottabad 27, 307-311. 